visual presentation, particularly in the field of professional education and this offering is a fairly recent example. As a now retired, long-serving, lay member of the mental health review tribunal (MHRT), I was interested to see what this combined product had to offer. However, before doing so, a word or two concerning the context may be helpful. When the Human Rights Act came into force in October 2000, it was hailed by the Government as an important means of giving citizens the right to challenge the activities of the State through the courts. At the time of its inception, some mental health lawyers thought the impact of the Act would provide considerable opportunities for challenge (a view put forward in the video). A more balanced view indicated that if tribunals followed the 'rules' correctly, little litigation would be likely to ensue. This seems to have been the case, since (as far as I have been able to ascertain informally) only a few cases await judicial review and these seem mainly concerned with matters of interpretation disclosure and delays. The booklet, of some 30 pages, to be read in conjunction with the video, deals with 'The Law of European Convention'; 'Possible Challenges'; 'Possible Defences'; 'Relevant Parts of the Human Rights Act'; 'Schedule 1 of the Act' and 'Judgments of the European Court of Human Rights'. I found the section devoted to the Law of the European Convention the most interesting. The other sections will be of most interest (and comprehension) to lawyers! I viewed the video in the company of my daughter (who is a lawyer, but does not specialise in mental health law) and her partner, who is a retired educationalist. The copy we received was of poor sound quality (I tried it on two different video machines to make sure it was the video and not the equipment). The introductory musical 'jingle' was very off-putting. However, for the most part, the presentation by four professionals (three experienced lawyers and an advocacy manager) was competent enough and easy to 'access'. However, the production's biggest weak ness was the fact that it was made prior to the actual implementation of the Act. It therefore really needs updating. Even allowing for the high cost of producing professional videos, it is very expensive. I do not imagine individuals will think they can afford it for their personal use, but training bodies may feel they should buy it - allowing for budgetary constraints. The pack is not without its merits and I shall probably donate mine to our regional tribunal office as a belated leaving present -1 retired a year ago!

Herschel Prins Loughborough, NottinghamTrent and Leicester Universities

\section{National Service Framework for Older People}

London: Department of Health. 2001. 194 pp. Free of charge.

This National Service Framework (NSF) is welcome. It confirms that the health and welfare of older people is to be addressed as a priority - and comes only fourth in the series of such publications - after cancer, coronary heart disease and mental illness. All the publications intend to improve services and reduce inequalities between services received by different groups in different parts of England.

Old age psychiatrists, and other professionals, have waited with eager anticipation for this publication's delivery, uncomfortable that older people and people with dementia had been excluded from the otherwise excellent NSF for Mental Illness. There were delays in delivery and 'false start' announcements of publication before Christmas 2000. All this added to the excitement and sense of moment. Momentous it has indeed proved, and interest has been heightened by controversy, antipathy and expressions of doubt from senior sources within the establishment of care of the elderly.

A great deal of work was undertaken by expert working groups - including members with diverging views. Their contributions were interpreted by civil servants and subject to the stamp of Professor Philp who was appointed Tzar toward the end of the process. These editorial intrusions have irritated some of the figures from the working groups, but they have resulted in a brave and fairly cohesive document, which will help us improve the health of older people and the services they receive. Our society and our government stigmatises and discriminates against older people, particularly those with mental illness and from disadvantaged groups and localities. This phenomenon is nailed.

Some health care professionals have sought to interpret 'equity' for old people in terms of admission to the same acute hospital wards as younger people. This false vision of equity is confronted.

Older people with serious mental illnesses of all kinds, including those who survive into later life with chronic or relapsing disorders, require the same discipline and quality of care guaranteed to younger people with mental illness by the NSF for Mental Illness.

The exclusion of older people from consideration by the NSF for Mental Illness is declared, politely, to be unacceptable.

A comprehensive framework ranges from health promotion to continuing and terminal care across the boundaries of personal, family, voluntary, social and health service responsibilities - pretty thrilling for a Department of Health publication. The practical implication of the NSF for Older People is the presence of a hierarchical strategy of implementation: national, regional and local mental health professionals are involved at all levels and should be included in working groups for all eight standards (and the group considering medication).

The process and its outcome will bond old age psychiatry more securely within health care for the elderly. Its interface with general psychiatry will benefit from clarification, informed by a determination that the best interests of individual patients and their families remain paramount

David Jolley Division of Old Age Psychiatry, Penn Hospital, Penn Road, Wolverhampton, West Midlands WV4 5HN

\section{Individual Statement Questions for MRCPsych Part 1}

By Maju Mathews. London: Royal Society of Medicine Press. 2002. 105 pp. $£ 14.95$

ISBN: 1-85315-505-5

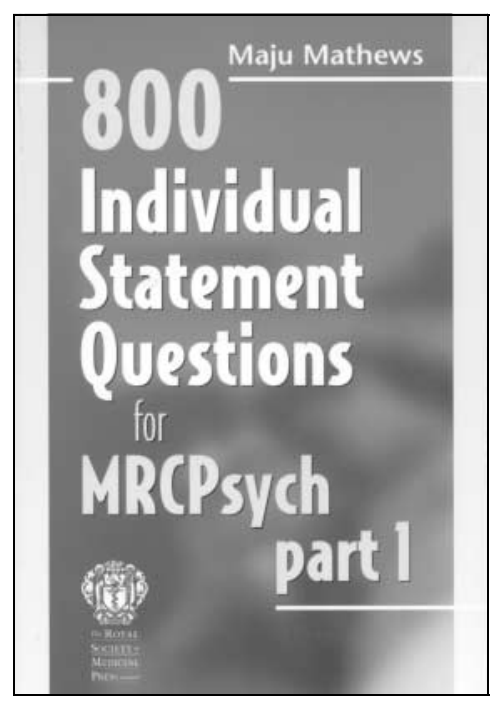

The multiple choice questions (MCQs) in both parts of the MRCPsych examination used to incite violence in hundreds of candidates who were unlucky enough to have to make sense of them. They seemed to be either excruciatingly obscure or so vaguely worded with 'clues', such as 'commonly', 'frequently', or 'not entirely unusual on the third Monday of an unusual month. ...', so as to be only understandable by James Joyce. And no one understands James Joyce!

Maju Mathews has tailored his book to the new MRCPsych Part I examination format. The book consists of four separate papers. A paper comprises 200 statements, each of which is answered as true or false.

Developing MCQ examination papers is a real headache. Getting the balance between the questions that a buffoon 